\title{
Validation of FORMOSAT-3/COSMIC level 2 "atmPrf" global temperature data in the stratosphere
}

\author{
U. Das ${ }^{1,2}$ and C. J. Pan ${ }^{1}$ \\ ${ }^{1}$ Institute of Space Science, National Central University, Jhongli-32001, Taiwan \\ ${ }^{2}$ Currently at Department of Physics, University of New Brunswick, Fredericton, New Brunswick, Canada \\ Correspondence to: C. J. Pan (cjpan@jupiter.ss.ncu.edu.tw) \\ Received: 5 May 2013 - Published in Atmos. Meas. Tech. Discuss.: 9 July 2013 \\ Revised: 12 January 2014 - Accepted: 28 January 2014 - Published: 12 March 2014
}

\begin{abstract}
GPS radio occultations by Formosa Satellite mission-3/Constellation Observing System for Meteorology, Ionosphere, and Climate (FORMOSAT-3/COSMIC) provide bending angle profiles, which are further processed to give profiles of temperature and water vapour in the lower atmosphere and electron density in the upper atmosphere. The level 2 "atmPrf" (atmospheric profile) product of version 2010.2640 gives temperature from surface to $0.2 \mathrm{hPa}$ $(\sim 60 \mathrm{~km})$. This is a dry temperature data product that does not include relative humidity in the inversion process and hence is reliable at altitudes $<100 \mathrm{hPa}$ and erroneous at lower altitudes. In the current study we compare the COSMIC “atmPrf" data from December 2010 to November 2011 with other satellite (SABER/TIMED and MLS/Aura) temperatures from 50 to $0.2 \mathrm{hPa}$, COSMIC "wetPrf" data and reanalysis (NCEP, ERA-Interim and UKMO) outputs at 100, 10,1 and $0.5 \mathrm{hPa}$ pressure levels. The satellite comparisons show that below $1 \mathrm{hPa}$ the observed median differences are most likely produced due to the biases in the retrievals of SABER and MLS. "atmPrf" and "wetPrf" temperatures compare extremely well in the common altitudes with differences being absolute zero between 200 and $10 \mathrm{hPa}$. When compared to reanalysis outputs, COSMIC seasonal means match NCEP and ECMWF seasonal mean temperatures very well, especially at 100 and $10 \mathrm{hPa}$. We conclude from this study that with the COSMIC dry temperature retrievals obtained from radio occultations of GPS, there is a $20 \mathrm{~km} \mathrm{ex-}$ tension of reliable data in the middle atmosphere. "atmPrf" data are of good quality and provide reliable and unprecedentedly large number of profiles at greater temporal and spatial resolutions for further studies and investigations of the middle atmosphere up to $1 \mathrm{hPa}$, i.e., approximately up to the stratopause at around $50 \mathrm{~km}$.
\end{abstract}

\section{Introduction}

Understanding the thermal structure of the lower and middle atmosphere is very important to understand the system and its dynamics. This knowledge is very important for climate change studies, troposphere-stratosphere and stratospheretroposphere exchange processes, coupling of lower to upper atmosphere, and vice versa, etc. Temperature measurements had been made from various ground-, rocket-, balloonand satellite-based platforms over the last few decades. Ground-based measurements by lidars (e.g., Hauchecorne and Chanin, 1980), provide very good accuracy but are present only over a few locations over land. Similarly, rocket (e.g., Clark and McCoy, 1965) and balloon (e.g., Rinsland et al., 1983) observations are also very sparse in space and time, although they provide the most accurate measurements. In addition, experiments from these platforms are very expensive. With the satellite era growing, observations from space (e.g., Dessler et al., 1998) are presenting a more global view and providing continuous measurements over all latitudes and longitudes.

Satellite temperature retrievals from atmospheric refractivity measurements using state-of-the-art technique, Global Positioning System based Radio Occultation (GPS RO) soundings, have provided the research community with a wealth of data to investigate the lower and upper atmosphere (Wickert et al., 2001, 2005). Comparisons with radiosonde measurements revealed that $\mathrm{RO}$ is a robust measurement technique for atmospheric monitoring and is sufficiently accurate to differentiate the variation in performance among various types of radiosonde (Kuo et al., 2005). The Formosa Satellite mission 3/Constellation Observing System for Meteorology, Ionosphere, and Climate 
(FORMOSAT-3/COSMIC) has further moved a step ahead providing temperature data with unprecedentedly large number of measurements using this technique (Anthes et al., 2008; Fong et al., 2009). COSMIC measurements provide good local time coverage, global coverage, high spatial, vertical and temporal resolutions, long-term stability, selfcalibration and capability to operate in all weather conditions. The inversion and error estimations of GPS RO data are discussed in detail by Kuo et al. (2004).

Earlier Kishore et al. (2009) validated the COSMIC "wetPrf" temperatures with reanalysis outputs of National Centers for Environmental Prediction (NCEP), United Kingdom Met Office (UKMO), and Japanese 25 years Reanalysis (JRA-25) in the altitude region from 8 to $30 \mathrm{~km}$, with emphasis on the $100 \mathrm{hPa}$ pressure level. They found that these COSMIC "wet" temperatures that include the relative humidity term in the inversion process best resembled the NCEP temperatures and were reliable up to $30 \mathrm{~km}$. Similar assessment was made with Vaisala-RS92 and Shanghai radiosonde temperatures and close-to-zero mean differences were observed in the troposphere and lower stratosphere (He et al., 2009). No rigorous validation studies have been done for the "dry" temperature, "atmPrf", data that omits the relative humidity term in the retrieval process. Only a few attempts were made using limited amount of data (e.g., Rao et al., 2009) in the lower stratosphere. In the current study, we are validating the latest version 2010.2640 level 2 "atmPrf" dataset, which gives "dry" temperature to much higher altitudes up to the lower mesosphere $(60 \mathrm{~km} / 0.2 \mathrm{hPa})$. Due to the omission of relative humidity, the data are erroneous at altitudes $>100 \mathrm{hPa}$. We thus concentrate on altitudes from 100 to $0.2 \mathrm{hPa}$. In this study we compare the COSMIC "atmPrf" temperature data from December 2010 to November 2011 with temperatures measured by Sounding of the Atmosphere using Broadband Emission Radiometry (SABER) instrument on board the Thermosphere-Ionosphere-Mesosphere Energetics and Dynamics (TIMED) satellite, Microwave Limb Sounder (MLS) instrument on board Aura satellite from 50 to $0.2 \mathrm{hPa}$, with the "wetPrf" temperatures between 300 and $3 \mathrm{hPa}$ and with reanalysis outputs of NCEP, ECMWF (European Centre For Medium-Range Weather Forecasts) Interim Reanalysis (ERA-Interim), and UKMO at 100, 10, 1 and $0.5 \mathrm{hPa}$ pressure levels on the seasonal scale. We show that COSMIC "atmPrf" temperatures are of good quality and provide unprecedentedly large number of observations to further the studies and investigations of the middle atmosphere up to the stratopause region $(\sim 50 \mathrm{~km})$ that were not possible earlier as reliable temperature data were available only up to $\sim 30 \mathrm{~km}$.

\section{Data and analysis}

\subsection{FORMOSAT-3/COSMIC temperature data}

The FORMOSAT-3/COSMIC mission comprises of a constellation of six micro satellites that were launched into a circular, $72^{\circ}$ inclination orbit at an altitude of $512 \mathrm{~km}$ on 15 April 2006. The mission goal was to deploy six satellites into six orbit planes at $800 \mathrm{~km}$ with a $30^{\circ}$ separation for evenly distributed local time coverage. Except for one satellite (FM-3), owing to solar panel related problems, all others have successfully achieved the proposed altitude. It is the first constellation of satellites for monitoring global weather and ionospheric electron density distribution using the GPS RO technique. Further details regarding the spacecraft constellation system can be obtained from Fong et al. (2009). COSMIC RO data are processed near real-time by the COSMIC Data Analysis and Archive Center (CDAAC) at the University Corporation for Atmospheric Research (UCAR) to give profiles of temperature and water vapour in the lower and middle atmosphere to be delivered to operational weather centers. CDAAC also reprocesses the data to retrieve bending angle, atmospheric refractivity, and finally water vapour and temperature in the lower atmosphere and electron density in the ionosphere.

The new version 2010.2640 level 2 "atmPrf" data product of COSMIC provides dry temperature from surface to $0.2 \mathrm{hPa}(\sim 60 \mathrm{~km})$, by neglecting the water vapour information, and hence is suitable for the investigations of stratosphere and lower mesosphere. Details of temperature retrieval from refractivity profile obtained from GPS RO sounding can be obtained in literature (Kursinski et al., 1997; Kuo et al., 2004; Anthes et al., 2008; Schreiner et al., 2010) and is briefly described as follows. Initially, L1 and L2 bending angle profiles are computed and then are linearly combined at common impact parameters to produce an ionosphere free bending angle profile versus impact parameter. During the retrieval process, this observational bending angle profile is differenced with a climatological bending angle profile to obtain the optimised bending angle. The mean and standard deviation of these bending angle differences are computed between 60 and $80 \mathrm{~km}$ altitude (where neutral atmospheric bending is negligible) and are used to estimate errors (that are reasonably assumed to be valid at other heights) for quality control purposes. The optimised bending angle is obtained in the height range defined by RO observations (exponentially extrapolated to $150 \mathrm{~km}$, if required) and subjected to Abel inversion (the large top height allows setting zero boundary condition at the top) to get the refractivity profile. Under the assumption of dry air, the retrieved refractivity is directly proportional to density. Pressure is then retrieved by integration of the hydrostatic equation and temperature is derived from the equation of state (Schreiner et al., 2010, and references therein). 
All COSMIC "atmPrf" temperature profiles from December 2010 to November 2011 are interpolated from 10 to $60 \mathrm{~km}$ at $0.1 \mathrm{~km}$ altitude spacing and 0.05 (in log scale) pressure spacing. Effectively the vertical resolution is $\sim 1 \mathrm{~km}$ in the middle atmosphere and the total number of profiles available during this period is more than 400000 . The profiles are gridded into four-dimensional space-time coordinates, i.e, latitude $\left(10^{\circ}\right)$, longitude $\left(10^{\circ}\right)$, altitude/pressure and local time $(2 \mathrm{~h})$. At each point in three-dimensional space, monthly averages for every two hours are computed that are later averaged over all local times to get the monthly means. These monthly means are then utilised to obtain the seasonal means during DJF (December 2010-February 2011), MAM (March-May 2011), JJA (June-August 2011), and SON (September-November 2011).

COSMIC level 2 version 2010.2640 "wetPrf" data obtained from one dimensional variational analysis that provides wet temperature from surface to $40 \mathrm{~km}$ (by including the relative humidity term) is also utilised in the current validation study. Comparison between the simultaneously retrieved "atmprf" and "wetprf" temperatures in the common altitudes is done to establish the consistency between the two data products. Differences between the two profiles are computed and medians and standard deviations of these differences are calculated to investigate this aspect.

The top row of Fig. 1 shows the global distribution of the number of COSMIC observations in space and time during the study period. Number of observations over the midlatitudes around $\pm 50^{\circ}(\sim 2000)$ is a factor of two higher than that over equator $(\sim 4000)$ and almost uniformly distributed in longitude and local time. The observations during the day over mid-latitudes are almost twice that over the equator at midnight. From a seasonal point of view, observations are highest during MAM and JJA.

\subsection{SABER/TIMED temperature data}

The TIMED satellite was launched in December 2001 into a circular orbit at $625 \mathrm{~km}$ with an inclination of $74.1^{\circ}$. The satellite makes $\sim 15$ orbits per day with a period of 1.6 hour and takes 60 days to complete a full $24 \mathrm{~h}$ cycle in local time. SABER is one of the four instruments onboard the TIMED satellite whose aim is to advance the understanding of the structure, energetics, chemistry and dynamics of the atmosphere from 20 to $120 \mathrm{~km}$. SABER measures the Earth limb emissions in 10 broad band radiometer channels ranging from 1.27 to $17 \mu \mathrm{m}$. The kinetic temperature from the tropopause to the lower thermosphere is retrieved from $\mathrm{CO}_{2}$ $15 \mu \mathrm{m}$ limb emission using a full non-local thermal equilibrium (non-LTE) inversion method. In the present study we have used the SABER 2A level data product of version 1.07 from December 2010 to November 2011. Comparison of the 1.07 version temperatures with other ground-based Rayleigh lidar observations showed that the SABER temperatures are higher than the lidar temperatures by 1 to $3 \mathrm{~K}$ in the lower stratosphere and slightly lower by 1 to $3 \mathrm{~K}$ in the upper stratosphere and lower mesosphere and it was concluded that the temperatures of this version are of good quality (Remsberg et al., 2008).

The middle row of Fig. 1 shows the global distribution of the number of SABER observations in space and time during the study period. Similar to the COSMIC coverage, the number of observations over mid-latitudes at $\pm 50^{\circ}$ latitudes is higher and very uniformly distributed in longitude. In contrast, observations are practically absent during noon at all latitudes and longitudes. This is due to the orbital nature of the TIMED satellite. From the seasonal point of view, higher number of observations is present during MAM in the Northern Hemisphere and during SON in the Southern Hemisphere.

\subsection{MLS/Aura temperature data}

The Earth Observing System (EOS) MLS is one among the four instruments onboard the NASA's EOS Aura satellite, launched on 14 July 2004 into a $705 \mathrm{~km}$ near-polar orbit. As Earth rotates underneath it, the Aura orbit stays fixed relative to the sun, to give daily global coverage with $\sim 14$ orbits per day and observations at fixed local time. MLS provides $\sim 3500$ vertical profiles each day up to a latitude of $82^{\circ}$ in each hemisphere (Waters et al., 2006). MLS temperature is retrieved from thermal microwave limb emission bands of $\mathrm{O}_{2}$ at $118 \mathrm{GHz}$ and $239 \mathrm{GHz}$. The isotopic $239 \mathrm{GHz}$ line is the primary source of temperature information in the troposphere, while the $118 \mathrm{GHz}$ line is the primary source of temperature in the stratosphere and above. In the current study we have used the version 3.3 temperature retrievals (Livesey et al., 2011) and focussed on the pressure levels from 100 to $0.1 \mathrm{hPa}$ from December 2010 to November 2011. The observed bias uncertainties (in $\mathrm{K}$ ) are 0 to $+1,-1$ to 0,0 to +5 , -7 to -4 and -8 to 0 at $100,10,1,0.316$ and $0.1 \mathrm{hPa}$ and precisions of this data product are $\pm 0.8, \pm 0.6, \pm 1, \pm 1$ and $\pm 2 \mathrm{~K}$, respectively at the five pressure levels (Schwartz et al., 2008).

The last row of Fig. 1 shows the global distribution of the number of MLS observations in space and time during the study period. Due to the fixed orbit of the Aura satellite, number of observations is constant at all latitudes and longitudes except at around $\pm 70^{\circ}$ where the satellite ascends/descends. Observations are available at all latitudes and longitudes only at 01:30 and 13:30 (local time). It can be concluded from Fig. 1 that COSMIC has a more uniformly distributed global coverage, especially in local time, in comparison to SABER and MLS observations and is due to the fact that COSMIC is a constellation of six micro satellites.

\subsection{NCEP reanalysis temperature data}

The NCEP/NCAR Reanalysis project uses state-of-the-art analysis/forecast system to perform data assimilation using 

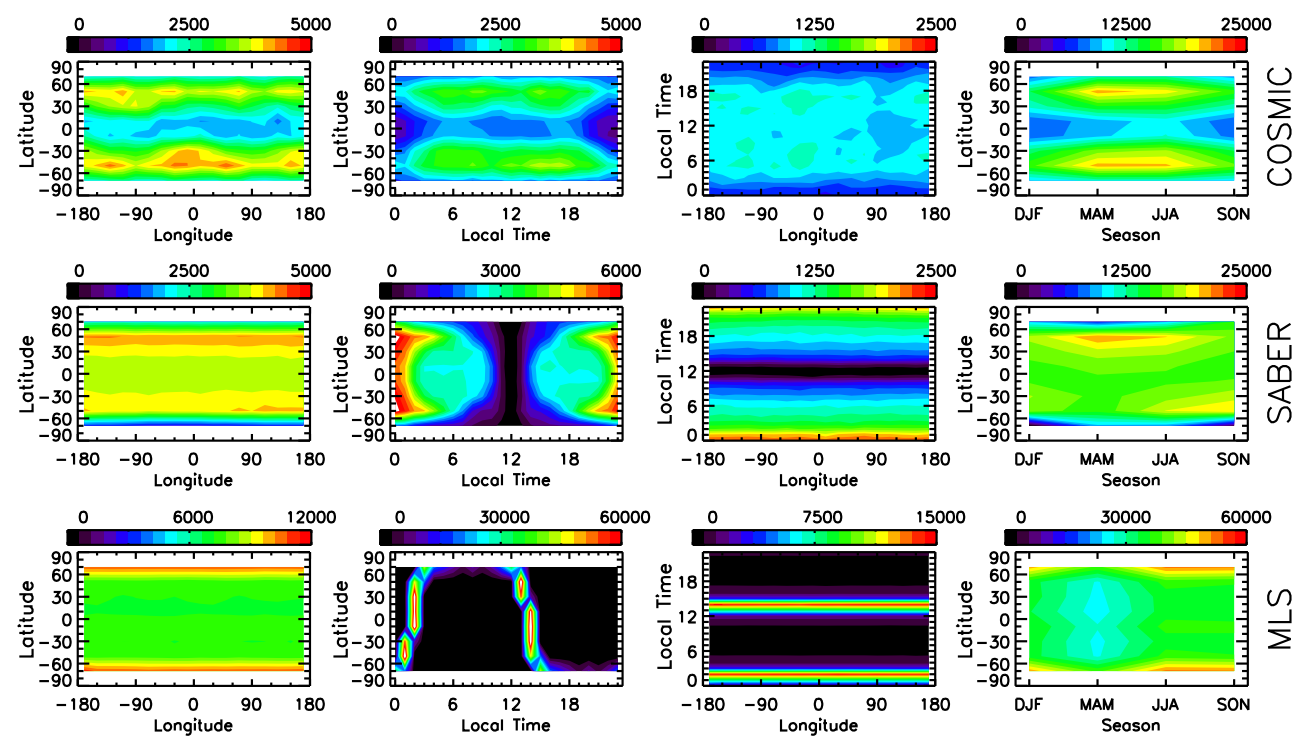

Fig. 1. The global distribution of number of temperature profiles from COSMIC (top row), SABER (middle row) and MLS (bottom row), with respect to space, time and season.

past data from 1948 to the present (Kalnay et al., 1996). A large subset of this data are available in its original 4 times daily format and as daily and monthly averages. The data are available at 17 pressure levels from 1000 to $10 \mathrm{hPa}$ on a $2.5^{\circ}$ latitude by $2.5^{\circ}$ longitude global grid. In the current study, seasonal averages are obtained from monthly averages for comparison with the COSMIC data at pressure levels 100 and $10 \mathrm{hPa}$ from December 2010 to November 2011.

\subsection{ERA-Interim temperature data}

ERA-Interim is a global atmospheric reanalysis produced by the ECMWF (Dee et al., 2011). The ERA-Interim project was conducted in part to prepare for a new atmospheric reanalysis to replace ERA-40, which will extend back to the early part of the twentieth century. These reanalysis data are produced with a sequential data assimilation scheme, advancing forward in time using 12-hourly analysis cycles. In each cycle, available observations are combined with prior information from a forecast model to estimate the evolving state of the global atmosphere and its underlying surface. This involves computing a variational analysis of the basic upper-air atmospheric fields (temperature, wind, humidity, ozone and surface pressure), followed by separate analyses of near surface parameters, soil moisture and soil temperature, snow and ocean waves. The analyses are then used to initialise a short-range model forecast, which provides the prior state estimates needed for the next analysis cycle. Data are available from 1979 onwards at 37 pressure levels from 1000 to $1 \mathrm{hPa}$ at a spatial resolution of $1.5^{\circ} \times 1.5^{\circ}$. In the current study, seasonal averages are obtained from monthly averages at pressure levels 100,10 and $1 \mathrm{hPa}$ for comparison with the COSMIC data from December 2010 to November 2011.

\subsection{UKMO stratospheric assimilated temperature data}

UKMO provides data concerning stratospheric temperature, geopotential height and wind components produced by the Stratospheric Data Assimilation System. The data assimilation system is a development of the scheme used at the Met Office for operational weather forecasting, which has been extended to cover the stratosphere by the Middle Atmosphere Group. The primary product is a daily analysis, at 12:00 UT, which is produced using only operational observations from 17 October 1991 onwards. These data are sets of meteorological analyses at 25 pressure levels from 1000 to $0.1 \mathrm{hPa}$ on a $2.5^{\circ}$ latitude by $3.75^{\circ}$ longitude global grid. In 2000 , the data assimilation system was converted to a 3-D Variational (3D-VAR) assimilation system that allows a statistically better combination of information from both observations and the model background (Lorenc et al., 2000; Swinbank and GB Met Office, 2002). In the current study, seasonal averages are obtained from monthly averages at pressure levels $100,10,1$ and $0.5 \mathrm{hPa}$ for comparison with the COSMIC data from December 2010 to November 2011.

\subsection{Analysis}

Temperature differences between COSMIC and SABER, and COSMIC and MLS are investigated using near-simultaneous measurements within $\pm 5^{\circ}$ latitude by $\pm 5^{\circ}$ longitude and one hour local time. These differences are grouped into different latitude regions $\left(-80^{\circ}\right.$ to $-50^{\circ},-50^{\circ}$ to $-20^{\circ},-20^{\circ}$ to $0^{\circ}, 0^{\circ}$ to $20^{\circ}, 20^{\circ}$ to $50^{\circ}, 50^{\circ}$ to $80^{\circ}$ ) and seasons (DJF, MAM, JJA, SON) and a statistical investigation is carried out by comparing the medians and their standard deviations. 

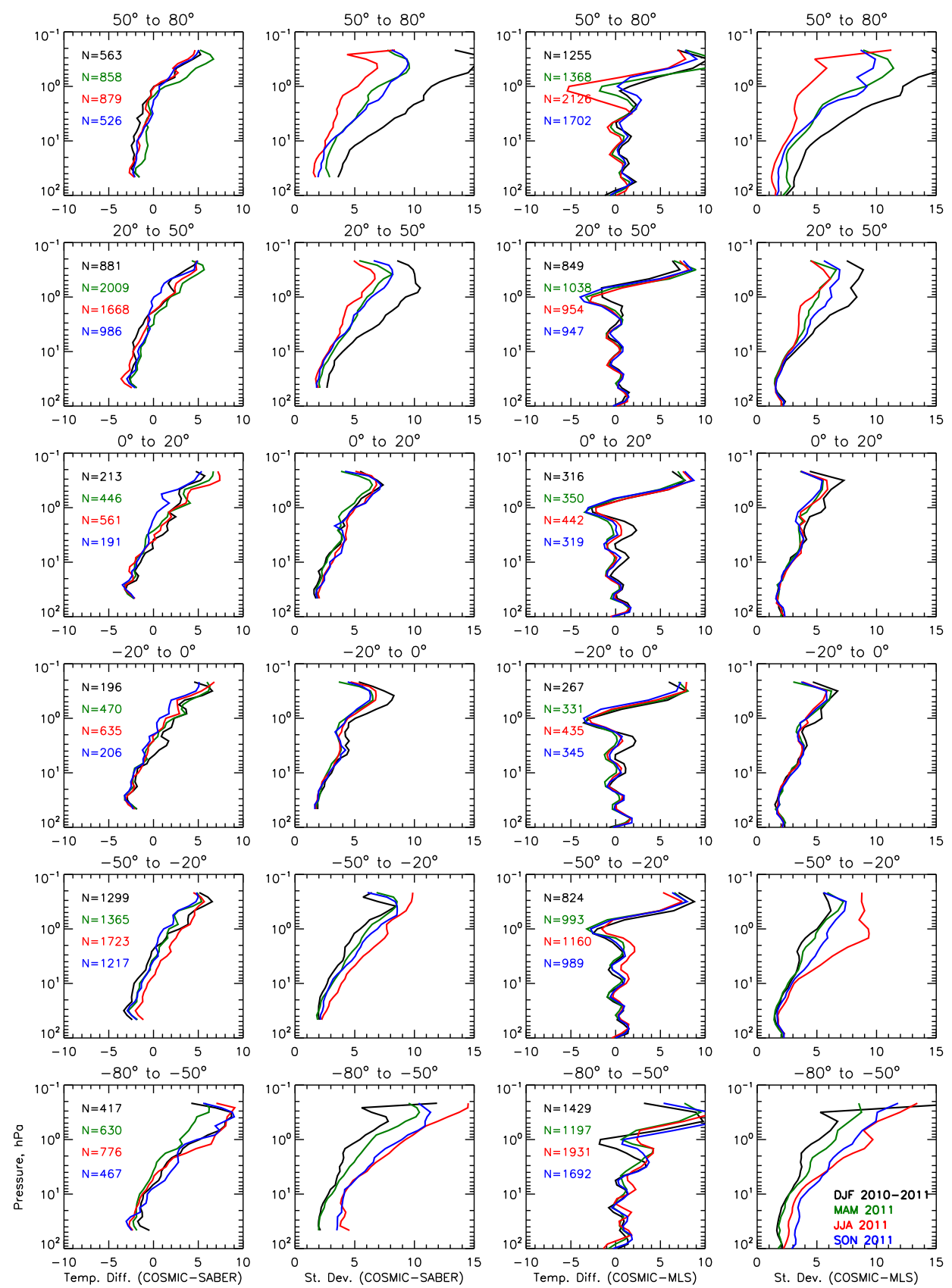

Fig. 2. Seasonal median differences between COSMIC \& SABER and COSMIC \& MLS temperatures obtained from near simultaneous observations in space and time (columns 1 and 3) and the corresponding standard deviations (columns 2 and 4 ) in different latitudinal regions (rows) and during different seasons (profile colour).

To compare COSMIC temperatures, which are gridded at a coarser spatial resolution, with those of NCEP, ERA and UKMO, the reanalysis seasonal means are under-sampled to match the latitude and longitude grid spacing of COSMIC means. Global comparisons are made at 100, 10, 1 and $0.5 \mathrm{hPa}$ pressure levels. NCEP data are available only at 100 and $10 \mathrm{hPa}$, ERA at 100, 10 and $1 \mathrm{hPa}$ and UKMO at all the four pressure levels of interest. The comparisons are made accordingly, by investigating the differences between seasonal mean temperatures of COSMIC and the different reanalysis outputs.

Finally, global mean temperature profiles from all the above listed satellites and reanalysis outputs are also compared with that of COSMIC. 


\section{Comparison with satellite temperatures}

The first and second columns of Fig. 2 show the seasonal median differences between COSMIC and SABER temperatures obtained from near simultaneous observations in space and time and the corresponding standard deviations, respectively. Measurements within $\pm 5^{\circ}$ latitude and longitude and one hour local time have been chosen for the comparison. The four profiles in each panel show the differences during different seasons - DJF (black), MAM (green), JJA(red), and SON (blue) - and different rows pertain to different latitudinal bands. No differentiation is made with respect to longitude and local time. In the left top corner are the numbers of profiles available for comparison during each season. Maximum numbers of simultaneous observations are available in $20^{\circ}$ to $50^{\circ}$ and $-50^{\circ}$ to $-20^{\circ}$ latitudinal bands, as the TIMED spacecraft yaws in about every 60 days to keep the instrument on the anti-sunward side of the spacecraft and latitude coverage extending from $53^{\circ}$ in one hemisphere to $83^{\circ}$ in the other flips over.

The seasonal median temperature differences in different latitude regions show that COSMIC temperatures are less than SABER temperatures by $2-3 \mathrm{~K}$ at lower altitudes $(\sim 50 \mathrm{hPa})$ and gradually increase with altitude to become higher by the same amount at $1 \mathrm{hPa}$. At higher altitudes of $\sim 0.2 \mathrm{hPa}$ the differences increase further to $5-7 \mathrm{~K}$ and in Southern Hemisphere high altitudes, the differences are as high as $10 \mathrm{~K}$. At $\sim 3 \mathrm{hPa}$ the differences are very close to zero. This pattern is very systematic in all latitude regions and during all seasons. The standard deviations over lowlatitudes are $\sim 2 \mathrm{~K}$ at $50 \mathrm{hPa}$, increase with altitude, are less than $5 \mathrm{~K}$ up to altitudes $>1 \mathrm{hPa}$ and maximum deviations of $6-7 \mathrm{~K}$ are observed at $\sim 0.5 \mathrm{hPa}$; at further higher altitudes they start to decrease. This pattern is also similar during all seasons. Over mid-latitudes also standard deviations at $50 \mathrm{hPa}$ are $\sim 2 \mathrm{~K}$ except in Northern Hemisphere winter $(\sim 3 \mathrm{~K})$ and increase with height. At $1 \mathrm{hPa}$ deviations vary from 5 to $10 \mathrm{~K}$ and maximise $(6-10 \mathrm{~K})$ at $\sim 0.5 \mathrm{hPa}$. In both hemispheres, summer deviations are lowest and winter deviations are highest at each pressure level. Over high-latitudes, deviations at $50 \mathrm{hPa}$ range from 2 to $4 \mathrm{~K}$ and maximise at $\sim 0.5 \mathrm{hPa}$. Largest deviations of $15 \mathrm{~K}$ occur during winter, while summer deviations are almost similar to that over midlatitudes.

Remsberg et al. (2008) compared SABER temperatures with ground-based lidar measurements and showed that SABER temperatures are higher by $1-3 \mathrm{~K}$ in the lower stratosphere (below $40 \mathrm{~km}$ or $\sim 3 \mathrm{hPa}$ ), similar at $40 \mathrm{~km}$, and lower by $1-3 \mathrm{~K}$ in the upper stratosphere and lower mesosphere (40-60 km). This is due to the bias error in $\mathrm{CO}_{2}$ radiances of the wide channel or Ch3 $\left(580-763 \mathrm{~cm}^{-1}\right)$ below $40 \mathrm{~km} \mathrm{com}-$ bined with a changeover from relying on both $\mathrm{Ch} 3$ and the narrow channel or Ch1 $\left(649-698 \mathrm{~cm}^{-1}\right)$ radiances at $40 \mathrm{~km}$ to relying on just $\mathrm{Ch} 1$ radiances at $50 \mathrm{~km}$ for the temperature retrievals (Mertens et al., 2001; Remsberg et al., 2008).
Interestingly, these biases and the systematic pattern in the median differences of COSMIC and SABER temperatures observed in the present study are very similar from 100 to $1 \mathrm{hPa}$. Above $1 \mathrm{hPa}$, the deviations are much larger indicating errors.

The third and fourth columns of Fig. 2 show the seasonal median differences between COSMIC and MLS temperatures obtained from near simultaneous observations in space and time and the corresponding standard deviations, respectively. Here the maximum numbers of simultaneous observations are present in the $50^{\circ}$ to $80^{\circ}$ and $-80^{\circ}$ to $-50^{\circ}$ latitudinal bands, due to the orbital nature of Aura satellite. The median differences are very small and oscillate between -1 and $+2 \mathrm{~K}$ up to $\sim 2 \mathrm{hPa}$ altitude in all latitude regions. At $1 \mathrm{hPa}$, COSMIC temperatures are less than MLS temperatures by $2-4 \mathrm{~K}$, equal at $0.6-0.7 \mathrm{hPa}$ and above this altitude, the differences are positive and large, and maximise (7-10 K) at $0.3 \mathrm{hPa}$. Seasonal differences are observed only in high latitudes and high altitudes $(<2 \mathrm{hPa})$. Standard deviations are less than $2 \mathrm{~K}$ from 100 to $20 \mathrm{hPa}$ in low- and mid-latitudes. They increase with altitude and at $1 \mathrm{hPa}$ are less than $5 \mathrm{~K}$ over low-latitudes and range from 5-9 K over mid-latitudes. Winter deviations over mid-latitudes are high and summer deviations are similar to those observed over low-latitudes. Over high-latitudes also, summer deviations are similar to those observed over low- and mid-latitudes while the winter deviations are the highest ( $>10 \mathrm{~K}$ at $1 \mathrm{hPa}$ ).

The oscillatory behaviour of the differences between COSMIC and MLS temperatures at altitudes below $1 \mathrm{hPa}$ is very similar to the oscillatory behaviour in the observed bias uncertainty of the MLS temperature biases (Livesey et al., 2011). The slightly larger negative difference at $1 \mathrm{hPa}$ and very high positive difference at $0.3 \mathrm{hPa}$ are also similar to the MLS bias uncertainties. Thus from the comparison of COSMIC temperatures with those from SABER and MLS measurements below $1 \mathrm{hPa}$, we can conclude that COSMIC temperatures are of greater quality, especially due to the reason that the observed differences are most likely produced due to the biases in retrievals of the latter.

Further, a straight forward comparison is done between the "atmPrf" and the "wetPrf" profiles of the COSMIC mission in the overlapping region. Left and right columns of Fig. 3 show the median temperature differences between these two simultaneously retrieved temperatures from the same GPS RO measurement and the corresponding standard deviations, respectively. Here also, the four profiles in each panel show the differences during different seasons - DJF (black), MAM (green), JJA(red), and SON (blue) - and different rows pertain to different latitudinal bands. No differentiation is made with respect to longitude and local time. In the left top corner are the numbers of profiles used for comparison during each season. It can be very clearly seen that from $200 \mathrm{hPa}$ to $10 \mathrm{hPa}$ the differences are absolute zero and standard deviations are $<1 \mathrm{~K}$ during all seasons and in all latitudinal bands. Below $200 \mathrm{hPa}$ differences and standard deviations 

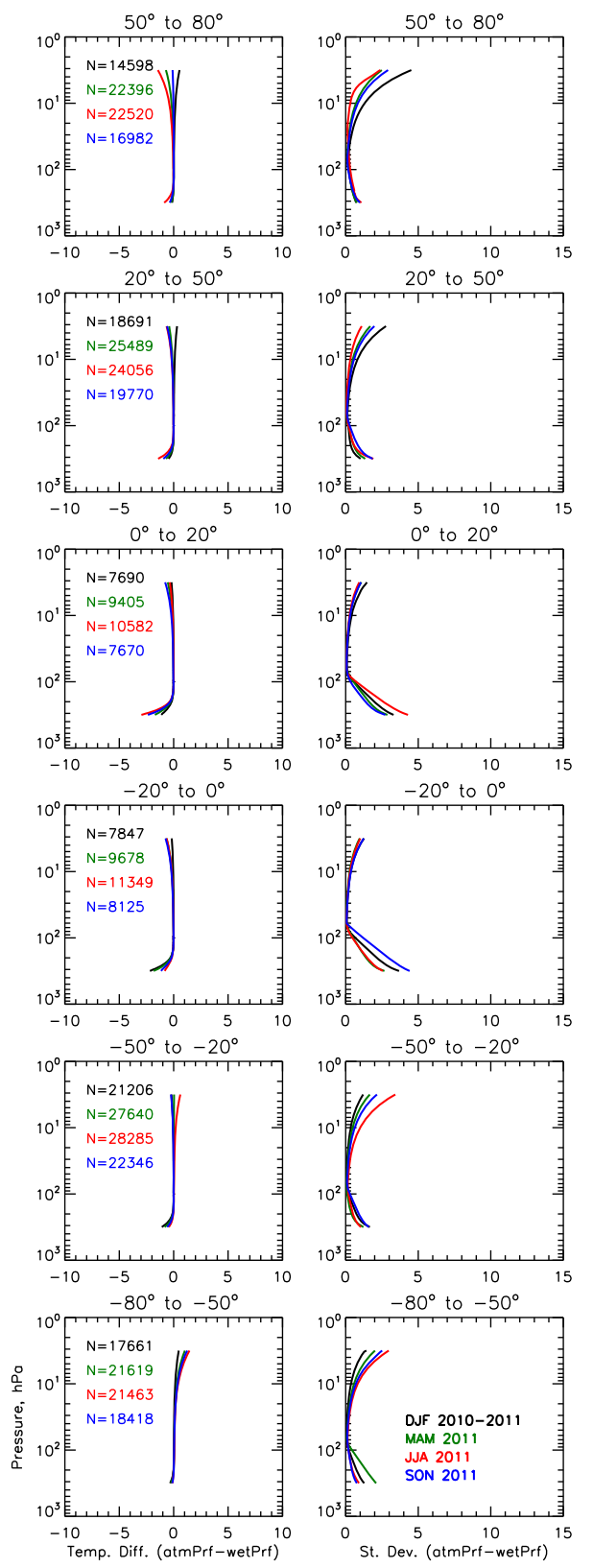

Fig. 3. Seasonal median differences between "atmPrf" \& "wetPrf" temperatures obtained from simultaneous retrievals (column 1) and the corresponding standard deviations (column 2) in different latitudinal regions (rows) and during different seasons (profile colour).

are $\sim-1 \mathrm{~K}$ and $\sim 2 \mathrm{~K}$, respectively, over mid- and highlatitudes and $\sim-3 \mathrm{~K}$ and $\sim 4 \mathrm{~K}$, respectively, in the tropics. This is due to errors in the "atmPrf" temperature retrievals that neglect water vapour at lower altitudes. At higher altitudes above $10 \mathrm{hPa}$, the differences are in the range of $\pm 1 \mathrm{~K}$ and standard deviations are in the range of $2-4 \mathrm{~K}$. This is due to the errors in the "wetPrf" retrievals at the higher altitudes. Thus it can be concluded that the dry atmospheric temperature product extends reliable COSMIC temperature data to higher altitudes. Further, both atmospheric temperature profiles can be combined not only at the statistical level but also at the individual profiles level, albeit with care, in between 100 and $10 \mathrm{hPa}$.

\section{Comparison with reanalysis outputs}

Figure 4 shows the global seasonal means of COSMIC temperatures and the various reanalysis outputs - NCEP, ERAInterim, and UKMO, at various pressure levels. At $100 \mathrm{hPa}$ (rows 1 to 4 from bottom), all temperatures are minimum over the tropics during all seasons and maximum in the summer high latitudes. During DJF and JJA, all temperatures look similar, both in variation and magnitude. However, during MAM and SON, COSMIC, NCEP, and ERA temperatures are similar while UKMO temperatures differ significantly, especially at high latitudes. At $10 \mathrm{hPa}$ (rows 5 to 8 from bottom), minimum temperatures are observed over winter high latitudes and maximum temperatures over summer high latitudes. Over tropics the temperatures do not show any significant seasonal variation. At this pressure level also, COSMIC temperatures are similar to NCEP and ERA temperatures, while UKMO temperatures vary significantly. At $1 \mathrm{hPa}$ (rows 3 to 5 from above) also, COSMIC and ERA temperatures match fairly well, while UKMO temperatures differ significantly. Maximum temperatures are observed in summer high latitudes and minimum temperatures in winter high latitudes with tropics showing no significant seasonal variation. And at $0.5 \mathrm{hPa}$ (rows 1 and 2 from above), we only have UKMO temperatures for comparison with COSMIC temperatures which show significant differences again. Maximum COSMIC temperatures are seen over southern high latitudes during SON and minimum temperatures observed during DJF in northern high latitudes.

Global differences between seasonal mean temperatures of COSMIC and the various reanalysis outputs at different pressure levels are shown in Fig. 5. Rows 1 to 3 from below show the temperature differences of COSMIC \& NCEP $(\mathrm{C}-\mathrm{N}), \mathrm{COSMIC} \& \mathrm{ERA}(\mathrm{C}-\mathrm{E})$, and COSMIC \& UKMO $(\mathrm{C}-\mathrm{U})$, respectively, at $100 \mathrm{hPa}$. Note the nonlinearity in the colour coding of the figure. Negative departures of NCEP from COSMIC are observed mostly over oceans and positive departures are observed over landmasses and are varying in the range from -2 to $1 \mathrm{~K}$. While no such land-ocean contrast is observed in case of comparison with ERA, the departures are very small ranging from -1 to $1 \mathrm{~K}$. UKMO temperatures are also reasonably well compared with COSMIC temperatures during DJF and JJA with differences ranging from -2 to $+2 \mathrm{~K}$. During MAM and SON also, the differences are in the same range over low and mid-latitudes; and over high latitudes, large differences greater than $\pm 5 \mathrm{~K}$ are observed. Rows 4 to 6 from below show similar temperature differences at $10 \mathrm{hPa}$. In contrast to that observed at $100 \mathrm{hPa}$, negative departures of NCEP from COSMIC are observed 

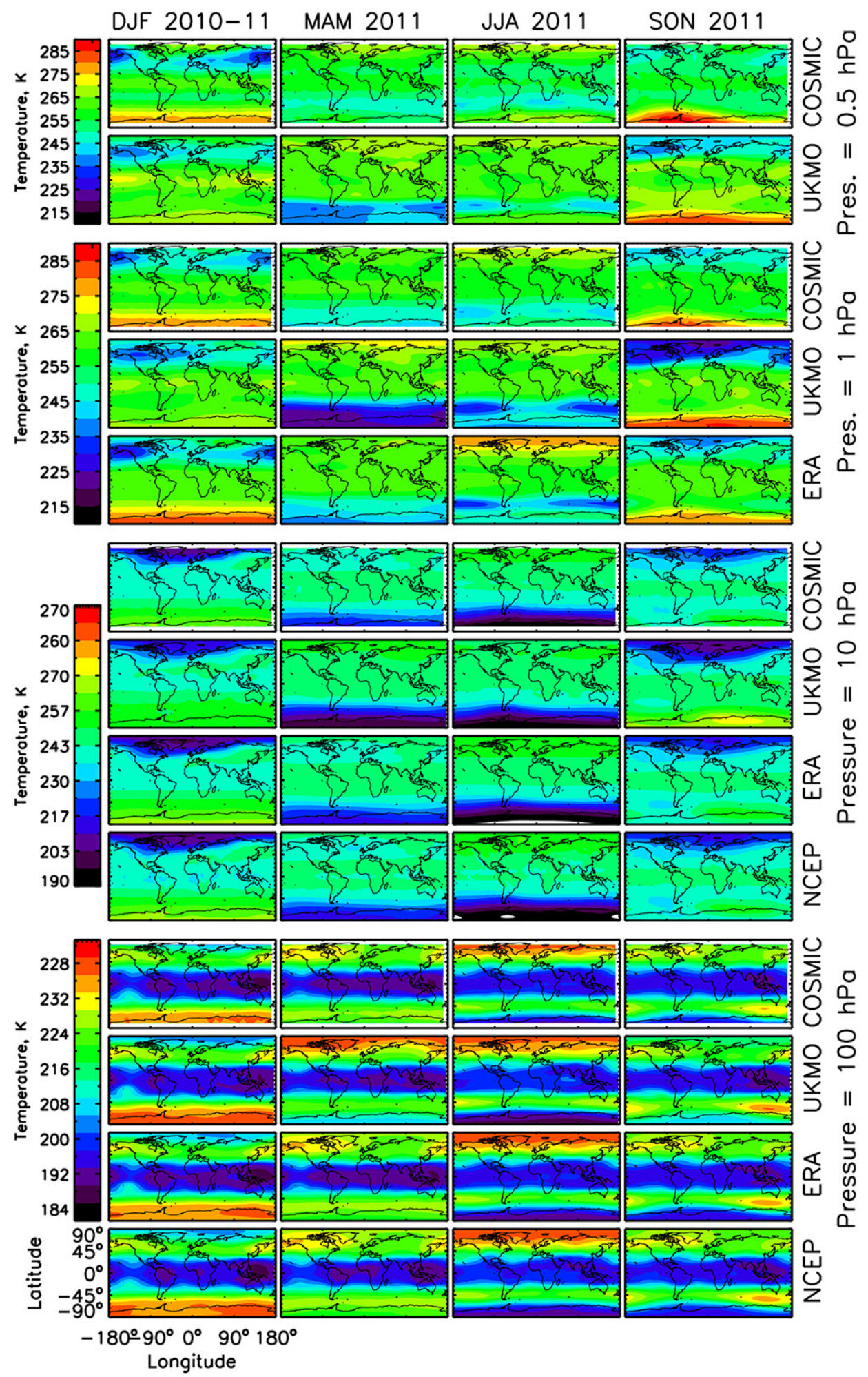

Fig. 4. Global seasonal means of COSMIC temperatures and the various reanalysis outputs - NCEP, ERA-Interim, and UKMO, at the pressure levels $100 \mathrm{hPa}$ (rows 1 to 4 from bottom), $10 \mathrm{hPa}$ (rows 5 to 8 from bottom), $1 \mathrm{hPa}$ (rows 3 to 5 from above) and $0.5 \mathrm{hPa}$ (rows $1 \&$ 2 from above). 


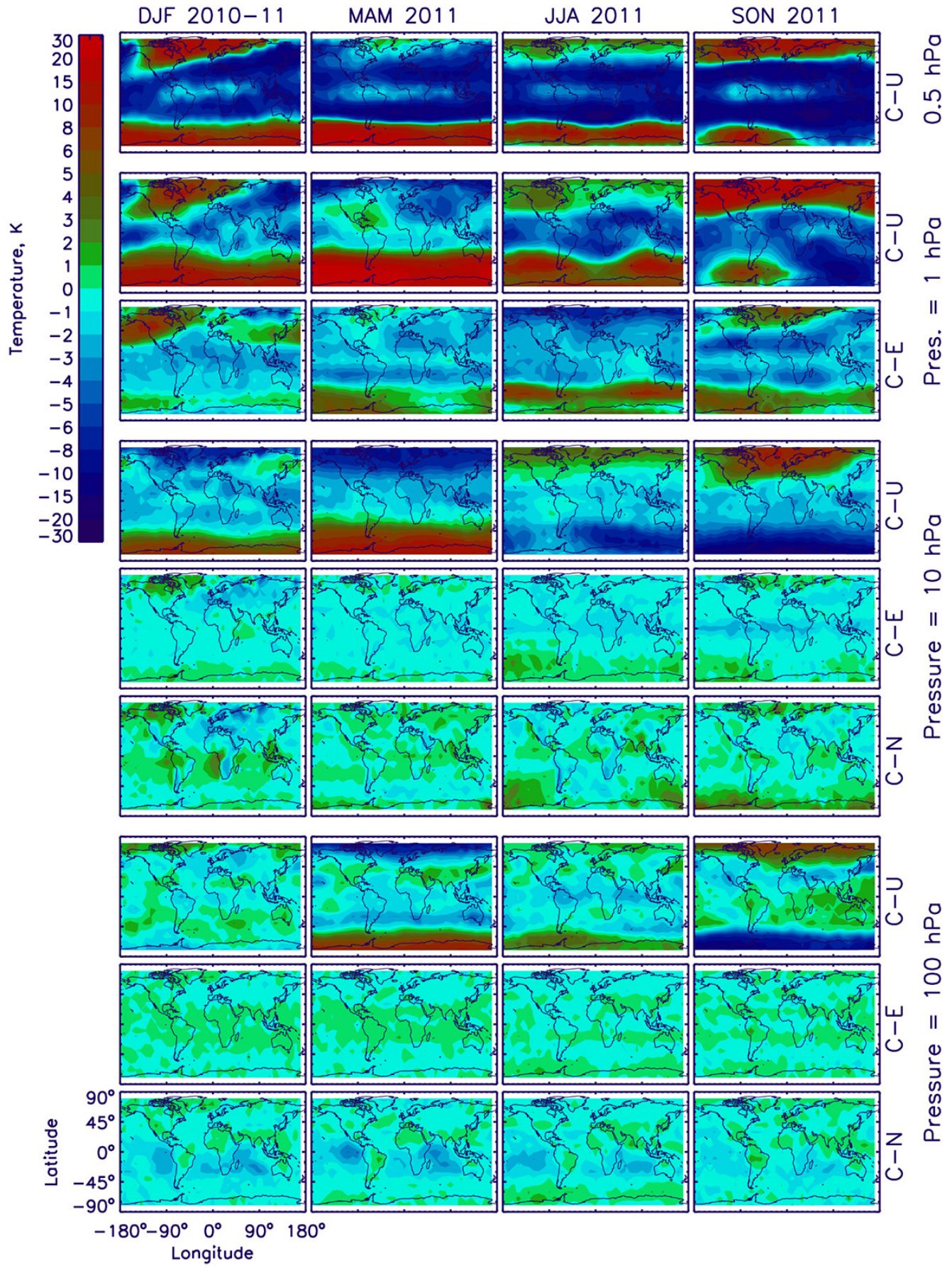

Fig. 5. Differences between the global seasonal means of COSMIC (C) and the reanalysis outputs - NCEP (N), ERA-Interim (E) and UKMO (U) - at $100 \mathrm{hPa}$ (rows 1 to 3 from bottom), $10 \mathrm{hPa}$ (rows 4 to 6 from bottom), $1 \mathrm{hPa}$ (rows $2 \& 3$ from above) and $0.5 \mathrm{hPa}$ (row 1 from above). Observe the nonlinearity in the colour coding.

mostly over landmasses and positive departures over oceans during all seasons and range from -3 to $3 \mathrm{~K}$. COSMIC and ERA temperatures compare very well at this level also during all seasons with differences in the range from -2 to $2 \mathrm{~K}$. And UKMO temperatures show reasonably good comparison with COSMIC temperatures only over low latitudes at this pressure level and the differences range from -3 to $0 \mathrm{~K}$. Over mid and high latitudes, COSMIC and UKMO temperatures differ significantly with differences being greater than $\pm 5 \mathrm{~K}$. COSMIC temperatures are greater in summer and vernal equinox and lower in winter and spring equinox. Rows 2 and 3 from above in Fig. 5 show the temperature differences of 


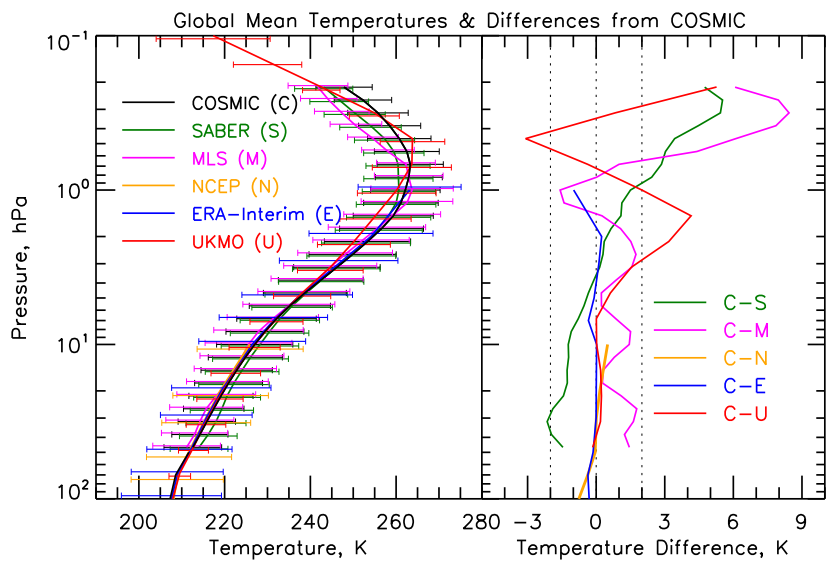

Fig. 6. Left: Global mean temperatures from COSMIC (C), SABER (S), MLS (M), NCEP (N), ERA-Interim (E) and UKMO (U). Right: Differences from the COSMIC global mean temperature.

COSMIC \& ERA $(\mathrm{C}-\mathrm{E})$ and COSMIC \& UKMO $(\mathrm{C}-\mathrm{U})$, respectively, at $1 \mathrm{hPa}$. Significant differences are observed between COSMIC and ERA with mostly negative departures over low and mid-latitudes ranging from -4 to $0 \mathrm{~K}$, large negative departures of about $8 \mathrm{~K}$ over northern high-latitudes during JJA and large positive departures of about $8 \mathrm{~K}$ over southern high-latitudes during all seasons except DJF, where the departures are small and about $2 \mathrm{~K}$. Very large differences greater than $\pm 10 \mathrm{~K}$ are observed between COSMIC and UKMO at $1 \mathrm{hPa}$. The situation is the same at $0.5 \mathrm{hPa}$ (Row 1 from above in Fig. 5), where we only have UKMO temperatures for comparison with COSMIC. The differences are greater than $\pm 10 \mathrm{~K}$.

From these figures we can summarize that COSMIC global seasonal temperatures match extremely well with those of ERA-Interim and very well with NCEP at 100 and $10 \mathrm{hPa}$ and reasonably well with ERA-Interim at $1 \mathrm{hPa}$. UKMO temperatures differ significantly except during DJF and JJA at $100 \mathrm{hPa}$.

\section{Global mean temperature}

Global mean temperatures are obtained by averaging the seasonal medians/means over all latitudes and longitudes from the various satellite observations and the reanalysis outputs and are shown in the left panel of Fig. 6. $1 \sigma$ standard deviations are also shown in the figure by horizontal bars. These bars are slightly shifted up/down along the pressure scale for proper perceptibility. All global means match extremely well and are within the $1 \sigma$ standard deviations. The differences of various global means from that of COSMIC are shown in the right panel of Fig. 6. Vertical dotted lines mark temperature differences at $-2,0$, and $2 \mathrm{~K}$ to aid the eye. All the differences, except those between COSMIC and UKMO temperatures, are well within the range from -2 to $+2 \mathrm{~K}$ up to $1 \mathrm{hPa}$, and are very high above this altitude. The trends observed in these differences are very similar to the earlier comparisons of the various seasonal medians/means.

1. SABER: COSMIC temperature is less than SABER temperature by $2 \mathrm{~K}$ at $50 \mathrm{hPa}$ and the difference reduces to zero at $3 \mathrm{hPa}$ with increasing height. At further higher altitudes, the differences are increasingly positive. At $1 \mathrm{hPa}$ COSMIC temperature is higher by $2 \mathrm{~K}$ and by almost $6 \mathrm{~K}$ at $0.3 \mathrm{hPa}$.

2. MLS: COSMIC temperatures are higher than MLS temperatures by 0 to $2 \mathrm{~K}$ from 50 to $2 \mathrm{hPa}$ and the differences are oscillating in this altitude region. At $1 \mathrm{hPa}$, COSMIC temperature is smaller by $\sim 2 \mathrm{~K}$ and larger by $\sim 2 \mathrm{~K}$ at $0.6 \mathrm{hPa}$. At $0.3 \mathrm{hPa}$ the difference is as high as $9 \mathrm{~K}$.

3. Reanalysis: Global COSMIC temperatures match extremely well with NCEP global mean and with ERA global mean up to $2 \mathrm{hPa}$ and also with UKMO global mean up to $7 \mathrm{hPa}$. The differences in these cases are very close to zero. At $1 \mathrm{hPa}$, COSMIC global mean is less than that of ERA mean by $1 \mathrm{~K}$. Maximum differences are seen in the comparison with UKMO above $7 \mathrm{hPa}$, where the UKMO mean deviates considerably and also oscillates. Peak differences are $4 \mathrm{~K}$ at $\sim 1.4 \mathrm{hPa},-3 \mathrm{~K}$ at $0.5 \mathrm{hPa}$ and $5 \mathrm{~K}$ at $0.2 \mathrm{hPa}$. Thus UKMO global mean matches with that of COSMIC only up to $7 \mathrm{hPa}$.

\section{Conclusions}

We have investigated the level 2 version 2010.2640 COSMIC "atmPrf" dry temperature data by comparing with other satellite (SABER/TIMED and MLS/Aura) temperature retrievals, the COSMIC "wetPrf" temperature, and reanalysis outputs (NCEP, ERA-Interim and UKMO). The local time coverage of COSMIC is highly uniform compared to other satellites as this is a constellation of six micro satellites. Median temperature differences between COSMIC and SABER in different latitude regions show that the COSMIC temperatures are lower than SABER temperatures by $2-3 \mathrm{~K}$ in the lower altitudes ( $>5 \mathrm{hPa}$ ) and greater by $2-3 \mathrm{~K}$ at higher altitudes $(1 \mathrm{hPa})$. From 5 to $1 \mathrm{hPa}$ the differences change from negative to positive. This pattern is very systematic in all latitude regions and during all seasons and probably arises from the biases in the SABER temperature retrievals. Similarly, median differences between COSMIC and MLS temperatures are also very similar to the bias uncertainties in the MLS temperature retrieval. The differences are very small below $\sim 2 \mathrm{hPa}$ and oscillate between -1 and $+2 \mathrm{~K}$; COSMIC temperatures are lower by $2-4 \mathrm{~K}$ at $1 \mathrm{hPa}$ and at $\sim 0.3 \mathrm{hPa}$ the COSMIC temperatures are greater by $7-10 \mathrm{~K}$. "atmPrf" and "wetPrf" COSMIC temperatures compare extremely well in 
the common altitudes with differences being absolute zero between 200 and $10 \mathrm{hPa}$. Comparisons with reanalysis outputs show that COSMIC temperatures match extremely well with ERA-Interim temperatures followed by NCEP temperatures. UKMO temperatures are either very high or low. From all these comparisons we conclude that COSMIC data can be used with confidence up to $1 \mathrm{hPa}$, i.e., approximately up to the stratopause $(\sim 50 \mathrm{~km})$. Above this altitude there are large deviations from the other satellite observations as well as reanalysis outputs. It is important to note that SABER and MLS temperatures are from limb radiance measurements and the reanalysis outputs are semi-empirical while COSMIC data are from GPS RO measurements. This strengthens the credibility of COSMIC data and emphasizes the capability of the GPS RO technique and also the efficiency and need for having not one but a constellation of such satellites for atmospheric sounding.

The COSMIC "wetPrf" data are retrieved mainly for the investigations of the troposphere. However, they are available up to $40 \mathrm{~km}$ and are reliable up to $\sim 30 \mathrm{~km}$, much above the tropopause (Kishore et al., 2009). The "atmPrf" dataset gives temperature up to $60 \mathrm{~km}$ and is reliable up to $\sim 50 \mathrm{~km}$ or $1 \mathrm{hPa}$ as the present study reveals, i.e., a $20 \mathrm{~km}$ extension of reliable data. This dataset aims at the investigations of the stratosphere and the current validation exercise shows that reliable temperature data is available up to the stratopause. It also shows that the "atmPrf" dataset is of great quality, and COSMIC provides unprecedentedly large number of observations spread uniformly in local time. This will open up new frontiers to investigate various geophysical processes in the stratosphere and the stratopause region. For example, in Kelvin wave studies using COSMIC "wetPrf" data (Das and Pan, 2013; Pan et al., 2011), conclusive results could not be drawn above $30-35 \mathrm{~km}$. The new "atmPrf" dataset, providing high quality data in the upper stratosphere, can be used for extending these investigations to high altitudes to obtain better insights in to the understanding of Kelvin wave propagation. Many other geophysical phenomena in 100 to $1 \mathrm{hPa}$ region can be better investigated with this dataset.

Acknowledgements. The authors thank Mr. S. S. Yang and Ms. Ling-Yun Cheng for their help and support. The authors acknowledge the UCAR/COSMIC programme, SABER/TIMED and MLS/Aura teams for providing free access to the temperature data, NOAA/OAR/ESRL PSD, Boulder, Colorado, USA, for the NCEP reanalysis data from their Web site at http://www.esrl.noaa.gov/psd/ and United Kingdom Meteorological Office (UKMO) for the stratospheric assimilated data through the British Atmospheric Data Centre (BADC). ECMWF ERA-Interim data used in this study have been obtained from the ECMWF data server. UD and CJP are supported by the NSC of Taiwan through grant NSC 102-2111-M008-015.

Edited by: C. von Savigny

\section{References}

Anthes, R. A., Ector, D., Hunt, D. C., Kuo, Y. H., Rocken, C., Schreiner, W. S., Sokolovskiy, S. V., Syndergaard, S., Wee, T. K., Zeng, Z., Bernhardt, P. A., Dymond, K. F., Chen, Y., Liu, H., Manning, K., Randel, W. J., Trenberth, K. E., Cucurull, L., Healy, S. B., Ho, S. P., McCormick, C., Meehan, T. K., Thompson, D. C., and Yen, N. L.: The COSMIC/FORMOSAT-3 Mission: Early Results, B. Am. Meteorol. Soc., 89, 313-333, 2008.

Clark, G. Q. and McCoy, J. G.: Measurement of Stratospheric Temperature, J. Appl. Meteorol., 4, 365-370, 1965.

Das, U. and Pan, C. J.: Strong Kelvin wave activity observed during the westerly phase of QBO - a case study, Ann. Geophys., 31, 581-590, doi:10.5194/angeo-31-581-2013, 2013.

Dee, D. P., Uppala, S. M., Simmons, A. J., Berrisford, P., Poli, P., Kobayashi, S., Andrae, U., Balmaseda, M. A., Balsamo, G., Bauer, P., Bechtold, P., Beljaars, A. C. M., van de Berg, L., Bidlot, J., Bormann, N., Delsol, C., Dragani, R., Fuentes, M., Geer, A. J., Haimberger, L., Healy, S. B., Hersbach, H., Hólm, E. V., Isaksen, L., Kållberg, P., Köhler, M., Matricardi, M., McNally, A. P., Monge-Sanz, B. M., Morcrette, J. J., Park, B. K., Peubey, C., de Rosnay, P., Tavolato, C., Thépaut, J. N., and Vitart, F.: The ERA-Interim reanalysis: configuration and performance of the data assimilation system, Q. J. Roy. Meteorol. Soc., 137, 553597, 2011.

Dessler, A. E., Burrage, M. D., Grooss, J.-U., Holton, J. R., Lean, J. L., Massie, S. T., Schoeberl, M. R., Douglass, A. R., and Jackman, C. H.: Selected science highlights from the first 5 years of the upper atmosphere research satellite (UARS) program, Rev. Geophys., 36, 183-210, 1998.

Fong, C. J., Yen, N. L., Chu, C. H., Yang, S. K., Shiau, W. T., Huang, C. Y., Chi, S., Chen, S. S., Liou, Y. A., and Kuo, Y. H.: FORMOSAT-3/COSMIC Spacecraft Constellation System, Mission Results, and Prospect for Follow-On Mission, Terr. Atmos. Ocean Sci., 20, 1-19, 2009,

http://www.ocean-sci.net/20/1/2009/.

Hauchecorne, A. and Chanin, M.-L.: Density and temperature profiles obtained by lidar between 35 and $70 \mathrm{~km}$, Geophys. Res. Lett., 7, 565-568, doi:10.1029/GL007i008p00565, 1980.

He, W., Ho, S.-P., Chen, H., Zhou, X., Hunt, D., and Kuo, Y.-H.: Assessment of radiosonde temperature measurements in the upper troposphere and lower stratosphere using COSMIC radio occultation data, Geophys. Res. Lett., 36, L17807, doi:10.1029/2009GL038712, 2009.

Kalnay, E., Kanamitsu, M., Kistler, R., Collins, W., Deaven, D., Gandin, L., Iredell, M., Saha, S., White, G., Woollen, J., Zhu, Y., Leetmaa, A., Reynolds, R., Chelliah, M., Ebisuzaki, W., Higgins, W., Janowiak, J., Mo, K. C., Ropelewski, C., Wang, J., Jenne, R., and Joseph, D.: The NCEP/NCAR 40-Year Reanalysis Project, B. Am. Meteorol. Soc., 77, 437-471, 1996.

Kishore, P., Namboothiri, S. P., Jiang, J. H., Sivakumar, V., and Igarashi, K.: Global temperature estimates in the troposphere and stratosphere: a validation study of COSMIC/FORMOSAT-3 measurements, Atmos. Chem. Phys., 9, 897-908, doi:10.5194/acp-9-897-2009, 2009.

Kuo, Y.-H., Wee, T.-K., Sokolovskiy, S., Rocken, C., Schreiner, W., Hunt, D., and Anthes, R.: Inversion and Error Estimation of GPS Radio Occultation Data, J. Meteorol. Soc. Jpn., 82, 507-531, 2004. 
Kuo, Y.-H., Schreiner, W. S., Wang, J., Rossiter, D. L., and Zhang, Y.: Comparison of GPS radio occultation soundings with radiosondes, Geophys. Res. Lett., 32, L05817, doi:10.1029/2004GL021443, 2005.

Kursinski, E. R., Hajj, G. A., Schofield, J. T., Linfield, R. P., and Hardy, K. R.: Observing Earth's atmosphere with radio occultation measurements using the Global Positioning System, J. Geophys. Res., 102, 23429-23465, doi:10.1029/97JD01569, 1997.

Livesey, N. J., Read, W. G., Froidevaux, L., Lambert, A., Manney, G. L., Pumphrey, H. C., Santee, M. L., Schwartz, M. J., Wang, S., Cofeld, R. E., Cuddy, D. T., Fuller, R. A., Jarnot, R. F., Jiang, J. H., Knosp, B. W., Stek, P. C., Wagner, A. P., and Wu, D. L.: Earth Observing System (EOS) Microwave Limb Sounder (MLS) Version 3.3 Level 2 data quality and description document, Tech. rep., Jet Propul. Lab., Pasadena, California, 2011.

Lorenc, A. C., Ballard, S. P., Bell, R. S., Ingleby, N. B., Andrews, P. L. F., Barker, D. M., Bray, J. R., Clayton, A. M., Dalby, T., Li, D., Payne, T. J., and Saunders, F. W.: The Met. Office global threedimensional variational data assimilation scheme, Q. J. Roy. Meteorol. Soc., 126, 2991-3012, 2000.

Mertens, C. J., Mlynczak, M. G., López-Puertas, M., Wintersteiner, P. P., Picard, R. H., Winick, J. R., Gordley, L. L., and Russell III, J. M.: Retrieval of mesospheric and lower thermospheric kinetic temperature from measurements of $\mathrm{CO}_{2} 15 \mu \mathrm{m}$ Earth limb emission under non-LTE conditions, Geophys. Res. Lett., 28, 13911394, 2001.

Pan, C. J., Das, U., Yang, S. S., Wong, C. J., and Lai, H. C.: Investigation of Kelvin waves in the stratosphere using FORMOSAT3/COSMIC temperature data, J. Meteorol. Soc. Jpn., 89A, 83-96, 2011.

Narayana Rao, D., Venkat Ratnam, M., Mehta, S., Nath, D., Ghouse Basha, S., Jagannadha Rao, V. V. M., Krishna Murthy, B. V., Tsuda, T., and Nakamura, K.: Validation of the COSMIC Radio Occultaion Data over Gadanki $\left(13.48^{\circ} \mathrm{N}, 79.2^{\circ} \mathrm{E}\right)$ : A Tropical Region, Terr. Atmos. Ocean. Sci., 20, 59-70, doi:10.3319/TAO.2008.01.23.01(F3C), 2009.

Remsberg, E. E., Marshall, B. T., Garcia-Comas, M., Krueger, D., Lingenfelser, G. S., Martin-Torres, J., Mlynczak, M. G., Russell, J. M., Smith, A. K., Zhao, Y., Brown, C., Gordley, L. L., LopezGonzalez, M. J., Lopez-Puertas, M., She, C. Y., Taylor, M. J., and Thompson, R. E.: Assessment of the quality of the Version 1.07 temperature-versus-pressure profiles of the middle atmosphere from TIMED/SABER, J. Geophys. Res., 113, D17101, doi:10.1029/2008JD010013, 2008.

Rinsland, C. P., Goldman, A., Murcray, F. J., Murcray, D. G., Smith, M. A. H., Seals Jr., R. K., Larsen, J. C., and Rinsland, P. L.: Stratospheric temperature profile from balloon-borne measurements of the 10.4- $\mu \mathrm{m}$ band of $\mathrm{CO}_{2}$, J. Quant. Spectrosc. Ra., 30, 327-334, doi:10.1016/0022-4073(83)90030-4, 1983.
Schreiner, W., Rocker, C., Sokolovskiy, S., and Hunt, D.: Quality assessment of COSMIC/FORMOSAT-3 GPS radio occultation data derived from single- and double-difference atmospheric excess phase processing, GPS Solut., 14, 13-22, doi:10.1007/s10291-009-0132-5, 2010.

Schwartz, M. J., Lambert, A., Manney, G. L., Read, W. G., Livesey, N. J., Froidevaux, L., Ao, C. O., Bernath, P. F., Boone, C. D., Cofield, R. E., Daffer, W. H., Drouin, B. J., Fetzer, E. J., Fuller, R. A., Jarnot, R. F., Jiang, J. H., Jiang, Y. B., Knosp, B. W., Krüger, K., Li, J. L. F., Mlynczak, M. G., Pawson, S., Russell, J. M., Santee, M. L., Snyder, W. V., Stek, P. C., Thurstans, R. P., Tompkins, A. M., Wagner, P. A., Walker, K. A., Waters, J. W., and $\mathrm{Wu}, \mathrm{D}$. L.: Validation of the Aura Microwave Limb Sounder temperature and geopotential height measurements, J. Geophys. Res., 113, D15S11, doi:10.1029/2007JD008783, 2008.

Swinbank, R. and Great Britian, Meteorological Office: A 3D Variational Data Assimilation System for the Stratosphere and Troposphere, Numerical Weather Prediction Division, Met Office, 2002.

Waters, J. W., Froidevaux, L., Harwood, R. S., Jarnot, R. F., Pickett, H. M., Read, W. G., Siegel, P. H., Cofield, R. E., Filipiak, M. J., Flower, D. A., Holden, J. R., Lau, G. K., Livesey, N. J., Manney, G. L., Pumphrey, H. C., Santee, M. L., Wu, D. L., Cuddy, D. T., Lay, R. R., Loo, M. S., Perun, V. S., Schwartz, M. J., Stek, P. C., Thurstans, R. P., Boyles, M. A., Chandra, K. M., Chavez, M. C., Chen, G.-S., Chudasama, B. V., Dodge, R., Fuller, R. A., Girard, M. A., Jiang, J. H., Jiang, Y., Knosp, B. W., LaBelle, R. C., Lam, J. C., Lee, K. A., Miller, D., Oswald, J. E., Patel, N. C., Pukala, D. M., Quintero, O., Scaff, D. M., Van Snyder, W., Tope, M. C., Wagner, P. A., and Walch, M. J.: The Earth Observing System Microwave Limb Sounder (EOS MLS) on the Aura satellite, IEEE T. Geosci. Remote, 44, 1075-1092, 2006.

Wickert, J., Reigber, C., Beyerle, G., König, R., Marquardt, C., Schmidt, T., Grunwaldt, L., Galas, R., Meehan, T. K., Melbourne, W. G., and Hocke, K.: Atmosphere sounding by GPS radio occultation: First results from CHAMP, Geophys. Res. Lett., 28, 3263-3266, doi:10.1029/2001GL013117, 2001.

Wickert, J., Beyerle, G., König, R., Heise, S., Grunwaldt, L., Michalak, G., Reigber, Ch., and Schmidt, T.: GPS radio occultation with CHAMP and GRACE: A first look at a new and promising satellite configuration for global atmospheric sounding, Ann. Geophys., 23, 653-658, doi:10.5194/angeo-23-653-2005, 2005. 